\title{
MOTIVATION AND RETENTION OF DENTAL OFFICERS IN THE INDIAN HEALTH SERVICE
}

\author{
By Donald C. Boggs, DDS, MPH, ${ }^{*}$ and M. Anthony Schork, $\mathrm{PhD}^{* *}$
}

\author{
In this report Drs. Donald Boggs and Anthony Schork have provided \\ administrators of public programs with a \\ pattern for motivating and retaining their staffs.
}

In 1955, responsibility for the health care of American Indians and Alaskan Natives was transferred from the Bureau of Indian Affairs to the U.S. Public Health Service and the Indian Health Service was established by Federal Legislation (P. L. 83-568). ${ }^{9}$ Since 1955, approximately 415 dental officers have been employed and subsequently separated from duty in the Indian Health Service.

The success of the dental program in the Indian Health Service depends on the motives, desires, morale or its lack, degree of satisfaction with job or its lack, social attitudes, professional goals, and interactions and reactions with coworkers and the Indian people by the 180 commissioned dental officers and a few available contracting practitioners.

After the conflict started in Vietnam, recruitment of dental officers for the Indian Health Service became relatively easy. This ease may be attributed, in part, to the opportunity for dental officers to fulfill their military obligation by serving two years in the Indian Health Service. The retention of dental officers and physicians in the Service for careers, however, has been a problem, particularly after the elimination of the draft of dentists and physicians in mid-1973.

The inducements to retain officers as career-people by improvement in morale, satisfaction with job, and, to a lesser extent, through increased pay, have been commendable. Little information appears available for determining (1) whether the dentists, on being recruited, actually are interested in a career with the Indian Health Service, (2) whether the dentists coming into the Indian Health Service are the ones best suited for treating Indian people, (3) whether the probability is that dental officers will or may not choose to make a career for themselves in the Indian Health Service, (4) what factors exist which will motivate dental officers to choose a career in the Indian Health Service or to leave it.

Because it became apparent that many more questions can be raised than can be answered in the early future, a study was planned to test specific hypotheses for determining (1) if important differences in satisfaction with job exist between dentists now in the Indian Health Service and those who have left it, and (2) which elements of satisfaction with one's job and which familial and demographic characteristics are related to motivation of dental officers for satisfying careers.

Guidelines also were developed to help determine where efforts for recruitment should be concentrated, and then aid in predicting through the prospective study the types of dentists who are apt to make a career of the Indian Health Service.

\section{A Review of Literature}

As an initial step, a search of the literature for information was completed. Blum and

\footnotetext{
${ }^{*}$ Chief, Area Dental Services Branch, Navajo Area Indian Health Service, P.O. Box G, Window Rock, Arizona 86515.

**Professor, Department of Biostatistics, School of Public Health, University of Michigan, 109 Observatory, Ann Arbor, Michigan 48104.
} 
Russ $(1942)^{2}$ investigated the relative importance that "gainfully employed" persons in New York City attached to the elements of incentives, salary, security, supervision, hours of work and advancement. Two-hundred eighty-six persons (181 men and 105 women) were asked to answer a questionnaire strictly in accord with their own feelings not with any generalized attitude known about the topic. The range of occupations of persons interviewed, though not stated, was reported to be complete. It varied from unskilled to professional groups. The elements of their job, ranked by the respondents in descending order of importance, were (1) advancement, (2) security, (3) salary, (4) supervisory relationship, and (5) hours of work. The attitude of employees was reported to change for sex, marital status, and age.

Although the study by Blum and Russ included a small sample of nonspecified groups of workers and the questionnaire included only five job-related factors, the conclusions agree with those of three other studies $1,3,4$ that employees consider factors such as advancement and security more important than salary. One may question how well the respondents in this study could differentiate between "how they felt" and their "general attitude on a topic." Some ambiguity in the wording of the questionnaire may have prohibited meaningful generalizations from the findings obtained by the study.

In contrast to the study by Blum and Russ, ${ }^{2}$ other studies ${ }^{7,8}$ have indicated that economic considerations outranked all others as reasons for quitting a job. Smith and Kerr $(1953)^{8}$ studied the reasons for employees quitting their jobs. They selected 200 different, nationally representative companies randomly from Poor's Publication for their study. Interviews on leaving these companies were studied to estimate, by a brief analysis of the content of a questionnaire, how often, in five typical interviews, each of 16 selected topics was mentioned as a reason for leaving. Forty-eight properly completed analyses were returned and utilized in the study. The major reasons for leaving in five representative interviews, as reported by the employees were (1) pay, (2) transportation, (3) promotion, (4) working conditions, (5) poor health, (6) security of the job, (7) friction with coworkers. The study did not state the criteria for defining a representative company, nor what was comprised in a geographical representation of the companies selected for the study. Only 48 out of 200 questionnaires were returned, properly completed, or could be used in the study.

Baehr $(1954)^{1}$ compared the attitudes of 134 employees, who consisted of five junior executives, 68 stenographers, 43 clerical workers, and $18 \mathrm{~m}$ iscellaneous workers in a large merchandising organization. The attitudes of the employees were assessed for 14 aspects of their working situation. A factor-analysis of the attitudes was provided on the 14 job-elements from which four factors were common to both groups: (1) employees' pride and interest in working for the company, (2) satisfaction related to belief that the job affords opportunity for personal growth and advancement in the organization, (3) human relations and technical aspect of immediate supervision, and (4) friendliness and cooperation of fellow employees. The study indicated that the minimum requirement for high morale of employees was that their needs and expectations are met in these four crucial factors.

Rosenstock and Miller $(1954),{ }^{6}$ in a study to determine why sanitary engineers leave this discipline, selected for an interview a random sample of 200 out of 1,700 graduates in sanitary engineering from the Northeastern United States and California. In addition, eight schools offering programs in sanitary engineering were chosen randomly and all sophomore, junior, and senior engineering students were interviewed. Rosenstock and Miller concluded that a majority of sanitary engineers were not leaving the discipline. Instead, they had not entered the discipline for which they were trained (sanitary engineering) upon graduation, perhaps because of a lack of knowledge of opportunities for jobs or from inadequate effort by employers to recruit them.

The engineers interviewed, ranked the value for the characteristcs of their job in 
descending order of importance as (1) interesting subject-matter, (2) coworkers from whom one can learn, (3) making important decisions, (4) doing independent work, (5) earning a large salary, (6) working in desirable geographical areas, and (7) having a maximum security in their job.

In an attitudinal survey by Shapiro $(1951)^{7}$ of 407 chemists, physicians, and biologists, the employees who had changed and who had not changed their jobs were asked to state the reasons for their decisions. The respondents gave greater weight to the nature and conditions of their work than to salary, especially the employees who had not changed jobs. In the array of reasons for quitting a job, on the other hand, economic considerations outranked all others. Even in this factor, however dissatisfaction with either the job or the conditions for working were mentioned about as frequently as dissatisfaction about earnings and advancement. Poor supervison and bad administrative policies, moreover, were the specific environmental factors most of ten cited as reasons for quitting a job.

Moore and Renck (1957), ${ }^{4}$ from a survey of natural scientists and engineers employed in industry, found that "technical competence of supervision" and "effectiveness of administration" were the sore spots. The scientists were not selected on a random basis because of limited numbers, but physicists, chemists and biologists were reported to be represented in about the same proportions as they were found in the rest of the country.

Rosen $(1963)^{5}$ surveyed with a highly structured mail questionnaire the entire professional staff of a corporate sponsored-research center - (105) chemists, physicians, electrical and mechanical engineers, and miscellaneous disciplines - to investigate the motivational significance of the factors in the job relevant for scientific and professional personnel in industry. The questionnaire contained 118 items which represented a summary of satisfaction with one's job. Rosen found that the major conditions of work considered to be "vital" were (1) interest in job, (2) salary for a comfortable living, (3) fair supervision, (4) salary based on merit, (5) permissive creativity in the job, (6) challenge of the job, and (7) equitable salary. The social status derived from their position also was reported to be unimportant for the professional staff. This study included a small sample of a selected group of individuals in a high socioeconomic status and must be treated as a nonrandom sample. The study did attempt, however, to gain information about several of the elements in a satisfactory job for individuals whose motivation for careers and for retention were highly desirable for the employer.

Howard $(1966)^{3}$ conducted a study of the conditions for "satisfier-duty" through a mail-questionnaire sent to approximately 98 percent of the career dental officers of the United Statcs (804) who were on active duty in the Army. Of the 804 questionnaires mailed, 687 (86.4 percent) were returned in time for evaluation. Each recipient rated the importance of each of 51 conditions of duty relevant to a satisfying military career. Out of the 51 specific items ranked in accordance with the officers' responses, the five most important items for the respondents were (1) high professional reputation of the Army Dental Corps, (2) sufficient pay to live comfortably, (3) superiors loyal to subordinates, (4) easy access to communication with superiors, and (5) chance of promotion to colonel. The study did not include data for dental officers who had separated from the Army.

Veira $(1971)^{10}$ attempted to determine the reasons of civil service employees and commissioned officers for terminating employment. Employees from five administrative areas (Aberdeen, Alaska, Billings, Oklahoma, and Phoenix) who left the service between January 1970 and December 1970 were requested to fill out a questionnaire voluntarily that was designated "reasons for leaving the service." Only 225 out of 515 (44 percent) of the potential respondents returned and filled out the questionnaire adequately for use in the final analysis. Of 109 commissioned officers, 67 physicians, 18 dentists, 10 engineer-sanitarians, and 14 other-classified employees, returned the questionnairc. The 
10 leading reasons reported by respondents for leaving the Indian Health Service were ranked in descending order of importance: (1) red tape and paperwork; (2) lack of material, equipment, and adequate facilities to do the job; (3) shortages of staff; (4) inadequate pay; (5) threat of frequent transferral; (6) limited training; (7) personal reasons, not related to service; (8) attitude of Indians; (9) political aspects; and (10) inequities of pay. Unfortunately, invalid completion and the low rate of return of the questionnaires prevented generalization to other employees of the Indian Health Service. The rate for returned questionnaires by commissioned officers was not stated.

\section{Purpose of the Study Now to Be Reported}

A study was developed to determine (1) the factors which were related to dentists' retention in the Public Health Service as measured by their perception of the factors in their job that were satisfying and dissatisfying, (2) personal, familial, or demographical variables which were related to dentists' retention in the service, and (3) based on the variables in this study, to learn whether one can predict which dentist will or will not stay in the Indian Health Service. A program then would be developed to reinforce satisfying factors and to eliminate or decrease the dissatisfying factors. The identification of significant personal, familial, or demographical variables, related to retention of dentists, should provide additional data for recruiting the type of dentist who is prone to choose a career in the Indian Health Service. For constructing the questionnaire to be used, the names and addresses were obtained of all dentists (415) who were in the Indian Health Service between the years 1955-1971. A questionnaire was constructed, pretested, and then revised on the basis of the findings in the studies of Howard ${ }^{3}$ and Veira ${ }^{10}$ because their studies were sufficiently applicable to the one planned. (See Questionnaire)

A statement with five alternatives in response was constructed for reach of the 34 elements of the job for the final questionnaire. A respondent's score of one and of two represent an attitude toward satisfaction equivalent to "extremely satisfactory" and "moderately satisfactory," respectively. A respondent's score of three represents a neutral attitude towards satisfaction which is equivalent to either "little or no satisfaction or dissatisfaction." A respondent's scores of four and of five represent an attitude towards satisfaction which is "moderately dissatisfying" and "extremely dissatisfying" respectively.

\section{DENTAL OFFICERS' QUESTIONNAIRE}

This questionnaire consists of two types of statements. One is merely backgroundinformation about age, education, size of home town, and familial status. The other type consists of statements followed by five possible responses. All responses should reflect your opinion about the degree of satisfaction or dissatisfaction that you feel the item contributes to a satisfying career in the Indian Health Service. The statements have no hidden meanings and should be answered in a straightforward manner. Please select responses, therefore, which reflect your honest opinion.

\section{Instructions}

For the purpose of this study the responses have the following meanings:

1. Extremely satisfactory-a condition or factor which you feel contributes significantly to satisfaction with a career in the Indian Health Service and actually would cause you to consider scriously a career or actually choose a career in the Indian Health Service;

2. Moderately satisfactory - a condition or factor which contributes moderately to to satisfaction with a career in the Indian Health Service;

3. Little or no satisfaction or dissatisfaction-a condition or factor which contributes little or nothing either to satisfaction or dissatisfaction;

4. Moderately dissatisfactory-a condition or factor that causes moderate dissatisfaction and would cause you to consider leaving the Service but you would not leave; 
5. Extremely dissatisfactory-a condition or factor which you feel would contribute sigificantly to dissatisfaction and, if uncorrected, would cause you to leave the Indian Health Service.

\section{Questions}

Please consider each condition carefully and then circle the number corresponding to the phrase which most nearly reflects your opinion about how this condition relates to a satisfying career in the Indian Health Service. Circle only one response for each item - one that is applicable to your experience or situation. Mark "NA" on items that you feel are not applicable and indicate your reason in Comments Sections at the bottom of page 5 of this questionnaire.

\section{Code to Use}

Extremely Satisfactory 1

Moderately Satisfactory 2

Neutral 3

Moderately Dissatisfying 4

Extremely Dissatisfying 5

1. Adequacy of dental materials and facilities

2. Sufficient pay to live comfortably

3. Pay commensurate with private practitioners

4. Adequacy of governmental housing

5. Availabitity of nongovernmental housing

6. Adequacy of quarters' allowance

7. Amount of paperwork and red tape

8. Providing dental care to Indians

9. Suitability of duties in the Indian Health Service

10. Suitability of duties to abilities

11. Your satisfaction with moving or transferring every two years

12. Your wife's satisfaction with moving or transferring every two years

13. Geographical location of assignments in Indian Health Service

14. Adequacy of dental equipment and facility

15. Maintenance of dental equipment

16. Type of duty performed at assignments in the Indian Health Service

17. Satisfaction with Indian-consumer participation or control of dental programs

18. Satisfaction with how Headquarters' staff implement Indian-consumer participation

19. Satisfaction with how Area staff implement Indian-consumer participation

20. Recreational opportunities at duty-stations

21. Option to retire after 20 years service regardless of age

22. Thirty days annual leave

23. No limit to sick leave

24. Station-leave

25. Adequacy of schools tor children

26. Fulfillment of draft obligation

27. Fair and equitable supervision

28. Wearing Public Health Service Uniform

29. Social interaction with fellow workers and Indian Health Service staff-members

30. Social interactions with Indians

31. Adequacy of opportunities for promotion

32. Recognition of accomplishments by supervisor

33. Opportunities for short-term training

34. Opportunities for long term training (specialization in dentistry)

\begin{tabular}{|c|c|c|c|c|c|}
\hline 1 & 2 & 3 & 4 & 5 & NA \\
\hline 1 & 2 & 3 & 4 & 5 & NA \\
\hline 1 & 2 & 3 & 4 & 5 & NA \\
\hline 1 & 2 & 3 & 4 & 5 & NA \\
\hline 1 & 2 & 3 & 4 & 5 & NA \\
\hline 1 & 2 & 3 & 4 & 5 & NA \\
\hline 1 & 2 & 3 & 4 & 5 & NA \\
\hline 1 & 2 & 3 & 4 & 5 & NA \\
\hline 1 & 2 & 3 & 4 & 5 & NA \\
\hline 1 & 2 & 3 & 4 & 5 & NA \\
\hline 1 & 2 & 3 & 4 & 5 & NA \\
\hline 1 & 2 & 3 & 4 & 5 & $N A$ \\
\hline 1 & 2 & 3 & 4 & 5 & NA \\
\hline 1 & 2 & 3 & 4 & 5 & NA \\
\hline 1 & 2 & 3 & 4 & 5 & NA \\
\hline 1 & 2 & 3 & 4 & 5 & NA \\
\hline 1 & 2 & 3 & 4 & 5 & NA \\
\hline 1 & 2 & 3 & 4 & 5 & NA \\
\hline 1 & 2 & 3 & 4 & 5 & NA \\
\hline 1 & 2 & 3 & 4 & 5 & NA \\
\hline 1 & 2 & 3 & 4 & 5 & NA \\
\hline 1 & 2 & 3 & 4 & 5 & NA \\
\hline 1 & 2 & 3 & 4 & 5 & NA \\
\hline 1 & 2 & 3 & 4 & 5 & NA \\
\hline 1 & 2 & 3 & 4 & 5 & NA \\
\hline 1 & 2 & 3 & 4 & 5 & NA \\
\hline 1 & 2 & 3 & 4 & 5 & NA \\
\hline 1 & 2 & 3 & 4 & 5 & NA \\
\hline 1 & 2 & 3 & 4 & 5 & $\mathrm{NA}$ \\
\hline 1 & 2 & 3 & 4 & 5 & NA \\
\hline 1 & 2 & 3 & 4 & 5 & NA \\
\hline 1 & 2 & 3 & 4 & 5 & NA \\
\hline 1 & 2 & 3 & 4 & 5 & NA \\
\hline 1 & 2 & 3 & 4 & 5 & NA \\
\hline
\end{tabular}


35. Indicate your present age if now on active duty, or age when you left the Public Health Service or retired. Age

36. Name of the town and state where you lived most of your adult life. Town: State:

37. Circle the number closest to the population of the town listed in Question 36.
1. Under 5,000
4. 25,000 to 49,999
2. 5,000 to 9,999
5. 50,000 to 149,999
3. 10,000 to 24,999
6. $150,000+$

38. Name of dental school(s) that you have attended

39. Your class grade, rank in dental school upon graduation:
(1) Top 10\%
(2) Top $20 \%$
(3) Top 30\%
(4) Top $40 \%$
(5) Top $50 \%$
(6) Top $60 \%$

40. Please indicate number of years credited towards retirement in the Public Health Service. (Do not include four years in dental school) Number of years:

41. Please indicate number of years spent in Service (Army, Navy, Air Force, Coast Guard, Civil Service) other than Pubiic Health Service that is credited towards retirement in Question 40. Number of $Y$ ears:

42. Location of last assignment in the Indian Health Service lapplicable only to those dentists who have transferred or resigned from the Indian Health Service):

Facility State

43. Circle the number which refers to your present Service-status:
1. Currentiy in the Public Health Service
2 Retired from Public Health Service
3. Transferred from Indian Health Service to another Division of Public Health Service
4. Now out of Public Heal th Service

44. Did you ask specifically for duty in the Indian Health Service? (1) Yes (2) No

45. Name of town where your wife has lived most of her adult life
Town:
State:

46. Please circle the number closest to the population of the town in question 45 .
1. Under 5,000
4. 25,000 to 49,999
2. 5,000 to 9,999
5. 50,000 to 149,999
3. 10,000 to 24,999
6. $150,000+$

47. Please circle the number which is closest to the combined current annual income of your father and mother.
1. Less than $\$ 5,000$
4. $\$ 20,000-\$ 39,999$
$2 \$ 5,000-\$ 9,999$
5. $\$ 40,000+$
3. $\$ 10,000-\$ 19,999$

48. Please circle the number which reflects the highest educational attainment of your father
1. Elementary School
4. Postgraduate
2. High School
5. Professional (M.D., D.D.S.)
3. College or University
6. Other

49. Please circle the number which reflects the highest educational attainment of your mother
1. Elementary School
4. Postgraduate
2 High School
5. Professional (M.D., D.D.S.)
3. College cr University
6. Other

50. Please circle either the number of dependents (wife, children, parents) you have, if you are still in the Service, or if you are a retiree, the number of dependents you had at the time you retired
1. One. 2. Two
3. Three
4. Four
5. Five or more

Comments:

\section{The Findings}

Of the 415 questionnaires mailed to the dentists, both those in and out of the Indian Health Service, 337 were returned in time for the analysis of data. The rate of return, hence, was 80 percent. The respondents were placed in one of six groups depending on the years toward retirement they had accumulated. Thirty-four percent (115) of the respondents were dentists who had served less than three years and presently were on 
duty in the Indian Health Service. Two dentists, 0.5 percent, had resigned after gaining nine or more years of credit toward retirement. Most of the noncareer officers, those with less than three years of service, were grade 0-3 (Lieutenant Senior Grade) officers. Of the 337 total respondents who returned the questionnaire, 115 ( 34.2 percent) had been in the Service less than three years and still were serving. Eight-eight (26.1 percent) of the respondents had been in the Service less than three years and had left. Twenty-six dentists (7.7 percent) had accrued between 3-9 years of credit toward retirement and still remained in the Public Health Service, whereas 69 (20.5 percent) had 3-9 years of credit and had left the Service. A further breakdown of the data indicated that only 15 dentists. ( 8.3 percent) of the 180 dentists presently in the Service had served from five to nine years. Thirty-seven (11 percent) of respondents had nine or more years of credit and two ( 0.5 percent) had accrued nine or more years of credit and had resigned from the Service.

Table 1 lists and ranks (based on the mean score for satisfaction of all respondents to each question) the 10 questions that score greatest in satisfaction (scores 1 and 2) and

\section{Table 1}

Ranking Order of The 10 Factors Contributing most

To Satisfaction and Dissatisfaction of Dentists

All Respondents: 1955-1972

Factors Contributing to Satisfaction

\begin{tabular}{|c|c|c|c|}
\hline $\begin{array}{l}\text { Rank } \\
\text { Order }\end{array}$ & $\stackrel{\mathrm{Q}}{\text { Number }}$ & $N$ & Question's Content \\
\hline 1 & 23 & 334 & No limit to sick leave \\
\hline 2 & $22^{*}$ & 334 & Thirty days annual leave \\
\hline 3 & $26 * * *$ & 311 & Fulfillment of draft-cobligation \\
\hline 4 & 24 & 332 & Station leave \\
\hline 5 & $8^{*}$ & 332 & Providing dental care to Indians \\
\hline 6 & $29^{* * *}$ & 333 & Social interaction with fellow workers \\
\hline 7 & 27 & 332 & Fair and Equitable Supervisor \\
\hline 8 & 31 & 324 & Opportunities for promotion \\
\hline 9 & $9^{* *}$ & 331 & Suitability of Duties in Service \\
\hline 10 & $16^{* *}$ & 335 & Type of duty performed \\
\hline \multicolumn{4}{|c|}{ Factors Contributing to Dissatisfaction } \\
\hline 1 & 12 & 291 & Wife's satisfaction with frequent moves \\
\hline 2 & $3^{* *}$ & 325 & Pay \\
\hline 3 & $7 * *$ & 333 & Paperwork and red tape \\
\hline 4 & $5 *$ & 255 & Availability of nongovernmental housing \\
\hline 5 & 11 & 332 & Dentist's satisfaction with frequent moves \\
\hline 6 & 25 & 333 & Adequacy of schools for children \\
\hline 7 & 17 & 316 & Participation of Indian Consumer \\
\hline 8 & $34^{* *}$ & 314 & Opportunities for long-term training \\
\hline 9 & 15 & 332 & Maintenance of dental equipment \\
\hline 10 & 18 & 314 & Headquarters' implementation of participation by Indian consumer \\
\hline
\end{tabular}

dissatisfaction (scores 4 and 5). Of the 10 factors related to satisfaction, six were statistically significant at the 0.05 to 0.001 level of probability when correlated with years of credit toward retirement. (See Table 1). These factors were (1) 30 days of annual leave, (2) fulfillment of military obligation for the draft, (3) providing dental care to Indians, (4) social interaction with fellow workers, (5) suitability of duties in the Indian Health Service, and (6) type of duty performed. Although the four remaining factors 
were not related statistically as contributing to satisfaction, they, nevertheless, are satisfying factors.

Of the 10 factors relating to dissatisfaction, four were statistically significant at the 0.01 to 0.001 level of confidence when measured against years of retirement gained: (1) pay, (2) paperwork and red tape, (3) availability of nongovernmental housing, and (4) opportunities for long-term training. The remaining six factors, from a practical view, should be considered dissatisfying factors although they probably were not dissatisfactions, which, when considered independently, contributed significantly to the dentists' decisions to leave the Indian Health Service. Question No. 4 probably is biased and should be discounted because the ambiguous wording induced many respondents not to score the question. Another consideration is that all dentists, especially some of the career dental officers, were not required to live in governmental housing.

Correlations were computed between the pertinent items of the questionnaire and the total number of years of credit toward retirement. These correlations, with their level of statistical significance indicated, are presented in Table 2. Clearly, the strongest relationships to number of years of credit toward retirement are for (1) age, (2) number of years of active duty spent in other services, (3) fulfillment of military obligation for the draft, (4) combined annual income of parents, and (5) opportunities for short-term training. The correlation with variable No. 2 might be expected from the definition of number of years of credit toward retirement.

Because of the way in which the score for satisfaction is developed, a negative correlation represents satisfaction with that particular variable by translation into more years of credit toward retirement. The negative $(-0.216)$ and significant correlation $(\mathrm{P}<0.001)$, however, indicate that the more satisfied the respondent was with the Indian Health Service as a mechanism to fulfill his draft-obligation, the fewer years of credit toward retirement he had accrued. The positive and large correlation (0.882) with age indicates obviously that the younger the respondent, the fewer the years of credit he has accrued.

Regardless of positive or negative correlation, the group-responses to individual items have to be analyzed separately in order to derive their meaning. Those items statistically correlated with number of years of credit toward retirement by a score of $\mathrm{P}<0.001$ $\mathrm{P}<0.01$ are (Table 2):

(1) pay commensurate with that of private practitioners $(-0.140)$;

(2) amount of paperwork and red tape (0.147);

(3) suitability of duties in the Indian Health Service $(-0.146)$;

(4) type of duty performed in assignments of the Indian Health Service $(-0.173)$;

(5) age (.888);

(6) social interaction with fellow workers and Indian Health Service Staff $(-0.155)$;

(7) opportunities for short-term training $(-0.193)$;

(8) fulfillment of military obligation for the draft $(-0.216)$;

(9) opportunities for long-term training $(-0.160)$

(10) population of town of dentist $(-0.170)$ (Note: Here, the negative correlation indicates that the smaller the town the more years of credit toward retirement.)

(11) educational attainment of dentist's mother $(-0.179)$ (Note: the negative correlation indicates that the higher the educational attainment the fewer years of credit.)

(12) number of years spent in other services (0.699);

(13) combined current annual income of dentist's mother and father $(-0.316)$ (Note: The greater the income of parents the shorter the time toward retirement accrued.)

(14) number of dependents (0.204).

Additional items significant at $\mathrm{P}<0.05$ are

(1) availability of nongovernmental housing $(-0.126)$;

(2) providing dental care to Indians $(-0.113)$; 
Table 2

Job-Factors, Kersonal, Demographic and Family Characteristics

Correlated With Total Number of Years of Retirement-Credit

(Total of the first 34 questions is $-0.147^{* *}$; NS-Not Significant, *P $<0.05,{ }^{* *}-P<0.01,{ }^{* *} P<0.001$ )

\begin{tabular}{|c|c|c|c|}
\hline \multicolumn{2}{|c|}{ A. Job-Factors } & \multicolumn{2}{|c|}{$\begin{array}{l}\text { Correlation- } \\
\text { Value }\end{array}$} \\
\hline & 1. Adequacy of Dental Materials & -0.0771 & NS \\
\hline & 2. Sufficient pay to live comfortably & $-0.060 i$ & NS \\
\hline & 3. Pay commensurate with private practitioners & -0.140 & ** \\
\hline & 4. Adequacy of government housing & 0.0991 & NS \\
\hline & 5. Availability of nongovernmental housing & -0.126 & - \\
\hline & 6. Adequacy of quarters allowance & 0.0381 & NS \\
\hline & 7. Amount of paperwork and red tape & -0.147 & $* *$ \\
\hline & 8. Providing dental care to Indians & -0.113 & - \\
\hline & 9. Suitability of duties in the Indian Heal th Service & -0.146 & ** \\
\hline & 10. Suitability of Duties to abilities & -0.077 & NS \\
\hline & 11. Your satisfaction with moving or transferring & 0.051 & NS \\
\hline & 12. Your wife's satisfaction with moving or transferring every two years & 0.008 & NS \\
\hline & 13. Geographical location of assignments in Indian Health Service & -0.053 & NS \\
\hline & 14. Adequacy of dental equipment and facilities & -0.125 & * \\
\hline & 15. Maintenance of dental equipment & 0.025 & NS \\
\hline & 16. Type of duty performed at assignments in the Indian Health Service & -0.173 & $* *$ \\
\hline & $\begin{array}{l}\text { 17. Satisfaction with participation of indian consumers or control of } \\
\text { dental programs by Indians }\end{array}$ & -0.074 & NS \\
\hline & 18. Satisfaction with how administrative staff at Headquarters level are & & \\
\hline & Implementing participation of Indian Consumers & -0.038 & NS \\
\hline & $\begin{array}{l}\text { 19. Satisfaction with how staff at Area-level are implementing participation } \\
\text { of Indian consumers }\end{array}$ & -0.035 & NS \\
\hline & 20. Recreational opportunities at duty station(s) & -0.057 & NS \\
\hline & 21. Option to retire after 20 years service & -0.057 & NS \\
\hline & 22. Thirty days annual leave & -0.119 & * \\
\hline & 23. No limit to sick leave (absence for sickness) & 0.010 & NS \\
\hline & 24. Station leave (absence for less than a full day) & 0.037 & NS \\
\hline & 25. Adequacy of schools for children & -0.073 & NS \\
\hline & 26. Fulfillment of military obligation for the draft & -0.216 & *** \\
\hline & 27. Fair and equitable supervision & 0.072 & NS \\
\hline & 28. Wearing the Public Health Service uniform & -0.079 & NS \\
\hline & 29. Social interaction with fellow workers and I ndian Health Service Staff & -0.155 & $* *$ \\
\hline & 30. Social interaction with Indians & -0.099 & NS \\
\hline & 31. Adequacy of opportunities for promotion & -0.075 & NS \\
\hline & 32. Recognition of accomplishments by supervisor & -0.010 & NS \\
\hline & 33. Opportunities for short-term training & -0.193 & $* * *$ \\
\hline & 34. Opportunities for long-term training & -0.160 & ** \\
\hline B. & Personal and Demographic Characteristics & & \\
\hline & 35. Age & .888 & *** \\
\hline & 36. Population of town where dentist has lived most of his life & -0.170 & ** \\
\hline & 39. Ranking by grade within dental class & -0.007 & NS \\
\hline & 41. Number years active duty spent in other services (Army, Navy, Air Force, etc.) & 0.699 & $* * *$ \\
\hline C. & Family-Characteristics & & \\
\hline & 46. Population of town where dentist's wife has lived most of her adult life & -0.115 & * \\
\hline & 47. Combined current annual income of dentist's mother and father & -0.316 & ** \\
\hline & 48. Highest educational attainment of dentist's father & -0.091 & NS \\
\hline & 49. Highest educational attainment of dentist's mother & -0.179 & * * \\
\hline & 50. Number of dependents claimed by dentist (wife, parents, children) & -0.204 & *** \\
\hline
\end{tabular}


Table 3

Job-Factors, Personal, Demographic, and Family Characteristics Correlated With

Number of Years of Credit Toward Retirement Exclusive of Military Service

(Total of the first 34 questions is $-0.147 *$ )

(NS = Not Significant, ${ }^{* P}<0.05, * * P<0.01, * * * P<0.001$ )

A. Job-Factors

Correlation-

Value

1. Adequacy of dental materials

$-0.048 \mathrm{NS}$

2. Sufficient pay to live comfor tably

3. Pay commensurate with private practice

-0.047 NS

4. Adequacy of governmental housing

-0.123 .

5. Availability of nongovernmental housing

-0.113 NS

6. Ad equacy of allowance for quarters

-0.119 .

7. Amount of paperwork and red tape

$0.067 \mathrm{NS}$

8. Providing dental care for Indians

9. Suitability of duties in the Indian Health Service

$-0.155 * *$

$-0.156 * *$

$-0.171 * *$

10. Suitability of duties to abilities

11. Your satisfaction about moving or transferring every two years

-0.063 NS

12. Your wife's satisfaction about moving or transferring every two years

0.044 NS

13. Geographical location of assignments in Indian Health Service

0.006 NS

14. Adequacy of dental equipment and facilities

$0.060 \mathrm{NS}$

15. Maintenance of dental equipment

16. Type of duty performed at assignments in the Indian Health Service

-0.106 NS

0.048 NS

17. Satisfaction with participation of Indian Consumers or control of dental programs by Indians

$-0.166^{* *}$

18. Satisfaction with how staff at Headquarters Level are implementing participation of Indian Consumers

-0.051 NS

19. Satisfaction with how staff at Area Levels are implementing participation of Indian Consumers

20. Recreational opportunities at duty station(s)

21 Option to retire after 20 years service regard less of age

22. Thirty days of annual leave

23. No limit to sick leave (absence for sickness)

24. Station leave (absence for less than a full day)

-0.026 NS

25. Adequacy of schools for your children

26. Fulfillment of obligation for the draft

27. Fair and equitable supervision

28. Wearing the Public Health Service uniform

29. Social interaction with fellow workers and Indian Health Service staff

30. Social interaction with Indians

31. Adequacy of opportunities for promotion

32. Recognition of accomplishments by supervisor

33. Opportunities for short-term training

34. Opportunities for long-term training (specialization in Dentistry)

$-0.019 \mathrm{NS}$

$-0.087 \mathrm{NS}$

$-0.175^{* *}$

-0.133 * *

$-0.022 N S$

0.007 NS

-0.059 NS

$0.190^{* *}$

0.075 NS

$-0.071 \mathrm{NS}$

$-0.157 * *$

-0.084 NS

-0.090 NS

-0.019 NS

$-0.228 * *$

-0.188 **

B. Personal and Demographic Characteristics

35. Age

36. Population of town where dentist has lived most of his life

$0.788 * * *$

$-0.194 * * *$

0.000 NS

39. Ranking by grades within dental class

0.366 ***

41. Number of years active duty spent in other services (Army, Navy, Air Force, etc.)

$-0.144 * *$

46. Population of town where dentist's wife has lived most of her adult life

47 Combined current annual income of dentist's mother and father

$-0.269 * *$

48. Highest educational attainment of dentist's father

49. Highest educational attainment of dentist's mother

50. Number of dependents claimed by dentist (wife, parents, and children)

-0.069 NS

-0.149 **

$0.238 * *$ 
Table 4

\section{Item-Analysis and Correlation-Values \\ (Correlation of factors No. 1-34 with the total of questions No. 1-34, NS - Not Significant, *-P<0.05, * $-P<0.01$, ** $-P<0.0011$}

A. Job-Factors

CorrelationValue

1. Adequacy of dental materials

2. Sufficient pay to live comfortably

3. Pay commensurate with private practitioners

4. Adequacy of government housing

5. Availability of nongovernmental housing

6. Adequacy of quarters allowance

7. Amount of paperwork and red tape

8. Providing dental care to Indians

9. Suitability of duties in the indian Heal th Service

10. Suitability of duties to abilities

11. Your satisfaction with moving or transferring every two years

12. Your wife's satisfaction with moving or transferring every two years

$0.394 * * *$

$0.383 * * *$

$0.380 * * *$

13. Geographical location of assignments in the Indian Heal th Service

$-0.043 \mathrm{NS}$

14. Adequacy of dental equipment and facilities

15. Maintenance of dental equipment

16. Type of duty performed at assignments in the Indian Health Service

$0.328 * * *$

$0.249 * * *$

$0.318 * * *$

$0.292 * * *$

$0.535 * * *$

$0.535 * * *$

$0.168 * *$

$0.161 * *$

$0.271 * * *$

$0.373 * * *$

$0.288 * * *$

17. Satisfaction with participation of Indian consumer or control of dental programs by Indians.

$0.481 * * *$

$0.347 * * *$

18. Satisfaction with how administrators at Headquarters level are implementing participation of Indian consumer.

$0.393^{* * *}$

19. Satisfaction with how administrators at Area level are implementing participation of Indian Consumer

20. Recreational opportunities at duty station(s)

21. Option to retire after 20 years service regardless of age

$0.303 * * *$

22. Thirty days annual leave

23. No limit to sick leave (absence for sickness)

24. Station leave (absence for less than a full day)

25. Adequacy of schools for children

26. Fulfillment of military obligation for the draft

27. Fair and equitable jupervision

28. Wearing the Public Health Service uniform

29. Social interaction with fellow workers and Indian Health Service staff

30. Social interaction with Indians

31. Adequacy of opportunities for promotion

32. Recognition of accomplishments by supervisor

33. Opportunities for short-term training

34. Opportunities for long-term training (specialization in dentistry).

$0.238 * * *$

$0.281 * * *$

$0.157 * *$

$0.234 * * *$

$0.298 * * *$

0.099 NS

$0.362 * * *$

$0.272 * * *$

$0.345 * * *$

$0.281 * * *$

$0.461 * * *$

$0.466 * * *$

$0.412 * * *$

$0.384 * * *$

Table 5

Variables with Significant Differences Between Respondents in Their Satisfaction With Job-Factors

\begin{tabular}{|c|c|c|c|}
\hline \multicolumn{2}{|l|}{ Factors } & $\begin{array}{l}\text { Value of } \\
\text { Chi-Square }\end{array}$ & $\begin{array}{l}\text { Level of } \\
\text { Significance }\end{array}$ \\
\hline 4 & Ad equacy of governmental housing. & 14.10 & $P \_0.01$ \\
\hline 15 & Maintenance of dental equipment $\ldots \ldots \ldots \ldots$ & 18.79 & $P<0.005$ \\
\hline 26 & Fulfillment of military obligation for the draft ... & 20.02 & $P-0.0005$ \\
\hline 27 & Fair and equitable supervision . ........... & 24.12 & $P-<0.0005$ \\
\hline 33 & Opportunities for short-term training $\ldots \ldots \ldots \ldots \ldots \ldots \ldots \ldots \ldots$ & 15.12 & $P_{-}<0.005$ \\
\hline 34 & Opportunities for long-term training $\ldots \ldots \ldots \ldots \ldots \ldots \ldots \ldots \ldots$ & 11.78 & $P-<0.05$ \\
\hline
\end{tabular}


(3) adequacy of dental equipment and facilities (-0.125);

(4) thirty days of annual leave $(-0.119)$;

(5) population of home town of dentist's wife $(-0.115)$. (Note: negative correlation indicates that the larger the town the fewer years toward credit for retirement.)

These items together with those significant at the 0.01 and 0.001 level represent the variables most strongly associated with years of credit toward retirement.

It should be noted that the correlation between the sum of all items in the questionnaire and years of credit toward retirement is $(-0.147)$, which indicates, with more years of credit, the more satisfied the officer becomes. The negative correlation results because the questions are scaled from one to five with one the most satisfied, while the score for credit toward retirement increases as the credit increases for an inversely related scoring. This score $(-0.147)$ indicates that the entire questionnaire (Nos. 1-34) is moderately associated with total credit toward retirement, but cannot be used to predict who will remain with the Indian Health Service.

An analysis of each item (question) with the total of the questions (Nos. 1-34) is summarized in Table 4. Most of the questions contribute about the same amount to the total (correlations about 0.300 ). The sum of questions $1-34$ only correlates at a level of about 0.15 with years of credit toward retirement. Several have higher correlations, namely, Nos. 9, 10,16, 22, 32, and 34. Two questions, Nos. 4 and 26 have very little association. If one is searching for a specific subset of factors which can be used to predict whether a dentist will stay with the Indian Health Service, he will find no sufficient subset. In this study, the seven questions Nos. 9, 10, 16, 31, 32, 33, and 34, however, may be used to form a core for a new questionnaire.

Chi-Square tests were computed to determine if there were any significant differences between the way the group of respondents scored on satisfaction or dissatisfaction in regard to factors 1-34. No significant differences were found between scoring on the variables by the responding groups according to years of credit toward retirement except for six factors (See Table 5);

These differences in reported satisfaction between the responding groups are not surprising because the respondents vary greatly in years of experience, responsibilities of job, aspirations in career, and reasons for being in the Indian Health Service.

\section{Some Discussion}

The successful administration of any program in the practice of public health must take into account the motivations and aspirations of the personnel in that program. The study, just reported, has attempted to analyze some of the factors which affect motivation and determine the retention of dentists in the Indian Health Service.

Based on the data collected in this study of 337 responding dentists, 10 satisfying and dissatisfying factors were identified and placed in a descending rank which was based on the mean score (See Table 1). Not all factors in this table were statistically relevant, when correlated with the number of years of credit toward retirement. All factors are of practical importance, however, in developing a program to retain dentists in the Service. Analyses for correlations were made to determine those variables which were statistically related to years of credit toward retirement. Some important and significant information then was identified. Many officers appeared to be in the Service because it supplied a mechanism for fulfilling their obligation in the draft as is indicated by the negative $(0.126)$ and significant correlation $(P<0.001)$. These data indicate that the more satisfied the respondents were with the Indian Health Service as a mechanism to fulfill their obligations to the draft the fewer years toward retirement had been accrued.

Major factors related to satisfaction follow:

(1) no limit to sick leave;

(2) thirty days of annual leave; 
(3) fulfillment of military obligation to the draft;

(4) station-leave (absence for less than a full day);

(5) Providing dental care to Indians;

(6) social interaction with fellow workers;

(7) fair and equitable supervision;

(8) opportunities for promotion;

(9) suitability of duties in the Indian Health Service;

(10) type of duty performed;

Major factors related to dissatisfaction now follow:

(1) wife's state of satisfaction with frequent moves;

(2) pay;

(3) paperwork and red tape;

(4) availability of nongovernmental housing;

(5) dentist's satisfaction with frequent moves;

(6) adequacy of schools for children;

(7) Indian-consumer participation;

(8) opportunities for long-term training;

(9) maintenance of dental equipment;

(10) Headquarters' implementation of participation by Indian-consumers.

The study indicates further that the larger the town from which the dentist and his wife came, and the greater the education and income that his family enjoys, the less likely he is to stay in the Service. Strong indications exist that dentists are more likely to make a career of the Indian Health Service if they come from rural areas and have families and parents with a low income and low educational attainment. Efforts in recruitment probably should be directed at the small dental schools located in the small towns, and preferably not from areas of high population.

Attempts to find a satisfactory equation for linear regression were unsuccessful because no subset of independent variables could be found to account for more than 50 percent of the variance. More factors, hence, need to be identified which contribute to the satisfaction and the retention of dentists. No single factor or simple subset of factors accounts for much of the variance and the study indicates further that no simple formula is available as a cookbook to the retention of dentists in the Service. On the basis of this study, one cannot predict which dentists will stay in the Service. Dentsits are individuals. They have separate and unique motives, aspirations, or lack of aspirations, and needs for ego which are basic in each one's personality. Retention of personnel in the health professions probably will have to be gained through a personal approach to the individual which takes into account the needs of each prospective employee. Variables identified in this study which are related to years of retirement could form a nucleus for a questionnaire in another study to determine additional factors important for retaining dentists, physicians, and the other health professions in the service.

\section{Recommendations for Improving the Retention of Dentists}

Five recommendations on retention of health personnel now can be pointed out:

1. variables identified in Tables 1,2 , and 3 as being satisfying should be reinforced and main tained;

2. yariables identified in Tables 1,2 , and 3 as being dissatisfying elements should be altered or corrected to help retain dentists in the Service;

3. variables $9,10,16,31,33$, and 34 should form the core for a new questionnaire to gain information on retention of health personnel;

4. insofar as possible, dentists probably should be recruited from small towns or from rural backgrounds;

5. each administrative area in the Service and each health board of a Service Unit should 
form a Committee of Indian Health Board and professional members to identify additional factors which might motivate dentists to stay in the Indian Health Service.

\section{Summary}

A Study in 1971 and 1972 has been reported which utilized a surveying questionnaire sent by mail to all dentists, both currently employed and separated from the Indian Health Service, to determine their perception of satisfaction or dissatisfaction regarding a list of 50 variables. These satisfying and dissatisfying variables and other selected personal, familial, and demographic variables were correlated with the number of years of credit toward retirement possessed by each dentist in the Public Health Service. A total of 415 dentists was identified as active in the Service or formerly Service-connected between 1955-1971. Of the 415 questionnaires mailed to these dentists 337 ( 80 percent) were returned in time for analysis of their data.

The 10 major factors related to the satisfaction of dentists was determined as (1) no limit to sick leave, (2) 30 days of annual leave, (3) fulfillment of military obligation for the draft, (4) station-leave (absence of less than a full day), (5) providing dental care to Indians, (6) social interaction with fellow workers, (7) fair and equitable supervision, (8) opportunities for promotion, (9) suitability of duties in the Indian Health Service, and (10) type of duty performed.

The 10 major factors related to dentists' dissatisfaction were (1) wife's extent of satisfaction with frequent moves, (2) pay, (3) paperwork and red tape, (4) availability of nongovernmental housing, (5) dentist's satisfaction with frequent moves, (6) adequacy of schools for the children, (7) participation of Indian consumers in control of program, (8) opportunities for long-term training, (9) maintenance of dental equipment, and (10) implementation of Indian-consumer in control of dental programs.

\section{Some Conclusions}

In view of the findings gained in this study on the variables related to retention of, and satisfaction or dissatisfaction of personnel, four conclusions now can be stated:

1. no single group of variables could be identified which predicts those dentists who either would make a career of, or leave the Indian Health Service;

2. variables were identified that could form a core for a questionnaire in another investigation of motivation and retention of health personnel by the Indian Health Service;

3. a number of personal, familial, and demographic variables were identified that could guide recruiting officers in selecting dentists who were likely to remain in the Indian Health Service; and

4. a number of satisfying and dissatisfying variables were identified that were related to years of credit toward retirement in the Indian Health Service.

\section{Bibliography}

1. Baehr, Melany E. A factorial study of the SRA employee inventory. Personnel Psychol., 7:319-36, Autumn 1954.

2. Blum, M. L., and Russ, J. J. A study of employee attitudes toward various incentives. Personnel J., 19:438-44, July 1942 .

3. Howard, R. L. Motivation elements in military dental officer careers. Military Surg., 131:259-67, Mar. 1966.

4. Moore, D. G., and Renck, Richard. The professional employee in industry. p. 138-50. (In Livingston, R. T., and Milberg, S. H. eds. Human relations in industrial research management. New York, Columbia University Press, 1957 . XI +418 p.)

5. Rosen, Hjalmar. Occupational motivation of research and development personnel. Personnel Administ., 26:37-43, Mar.-Apr. 1963. 
6. Rosenstock, I. M, and Miller, A. P. Why some sanitary engineers leave the field. PHS Monograph No. 21. Washington, Government Printing Office, Apr. 1954.16 p.

7. Shapiro, Theresa R. The attitude of scientists toward their jobs.p. 151-62. (In Livingston, R. T., and Milbers. S. H., eds. Human relations in industrial research mangement. Ncw York, Columbia University Press, 1957. XI + 418 p.)

8. Smith, F. J., and Kerr, W. A. Turnover factors as assessed by the exit interviews. J. Applied Psychol., 37:352-5, Oct. 1953.

9. U.S. Public Health Service, Indian Health Service. Dental services for American Indians and Alaska natives; annual report, fiscal year 1970. PHS Publ. No. 1870, Washington, Government Printing Office, n.d. VII + 52 p. (p. 1$)$

30. Veira, T. A. Reasons for leaving the service: a descriptive analy sis of why indiviudals leave Indian Health Service imployment. Prepared by the Office of Systems Development, Alaska Native Health Service, Indian Health Service, Anchorage, Alaska, n.d. 26 p. mimeog.

\section{The Gazette Takes a Bow}

Volume 1. No. 1, of the Publication of the Michigan Chapter of the American Society of Preventive Dentistry says the Society's mission is to reduce the incidence of dental disease by reducing the causative factors. Its goals, hence, are 1, to further the education of the dental profession in order to improve the delivery of preventive services, 2 , to educate the public about the value and application of preventive dentistry, 3 , to build and maintain a viable organization dedicated to preventive dentistry, 4 , to serve as a moving force to unite the energies and resources of those public and private agencies with special interest in oral health, and, 5, to promote further research into the prevention of dental disease. (The Gazette for February, 1974)

\section{More About Oral Biology}

President Philip Boyne reminds interested dentists of the 31st Annual Meeting of the American Institute of Oral Biology at Palm Springs, California, October 25-29. Four well-informed essayists will serve as instructors and cover a wide spectrum of new information. Further information and applications are available from Membership Chairman, P. O. Box 897, Glendora, California 91740. (Announcement of April 1, 1974)

\section{"Caries Research"}

In March, the Editor of the Journal of Public Health Dentistry received complimentary copies of the quarterly journal "Caries Research" (95p.) and its Supplement, titled "Reports of ORCA on Water Fluoridation" (35p.) - a Journal of the European Organization for Caries Research. Inasmuch as the paper of this publication and its reproduction of photographs are excellent, and well-known scientists are contributing the articles, some readers may be interested. The publisher, S. Karger A. G., Arnold-BlocklinStrasse 25, CH-4011 Basel, Switzerland, announces an introductory offer to members of NAD in 1974 at $\$ 17.50$. (Announcement received March 27, 1974) 